exceptions. In all the others the obstruction, if present, must have been due to something inherent in the tube itself. This is probably to be found in strong contraction of the circular fibres of the gullet at the upper part of the sesophagus. In two cases-those of Fitz (Case 8 in table), and of Wilkinson King (Case 3) - there was tetanic spasm, affecting in the one the flexors of the limbs and in the other the abdominal muscles; and it need hardly be pointed out that if such a condition existed at the same time in the muscular walls of the gullet rupture would be likely to take place." In writing the above Mackenzie must have forgotten that the cramp did not come on till long after the occurrence of the rupture- on the seventh day of the illness in Fitz's case, and after the onset of pain and dyspncea in that of Wilkinson King. Mackenzie endeavoured to found his view on a basis of experiment by testing a number of normal gullets removed post mortem in order to find out at what point and in what manner they underwent rupture when overstrained by excessive pressure from within. He concluded (1) that rupture by direct pressure applied within the œsophagus always takes place in a longitudinal direction; (2) that the rent never occurs in the upper part of the tube and in most cases is confined to the lower third; and (3) that the mucous membrane offers greater resistance to strain than the muscular covering.

Before dismissing from our attention the valuable work of Mackenzie on this subject, it is only right to say that, in rejecting the auto-digestion theory of Zenker and von Ziemssen, he has quite failed to grasp the exact nature of their position. He quotes them as considering that the accident results chiefly from "intra-mortem cesophageal malacia," or softening of the coats from peptic solution in the last hours of life. But the German authors distinctly lay down " "that cesophago-malacia may be developed in rare cases intra vitam in a patient who is perfectly well, without any connexion with any preceding serious disease, and form the basis of the so-called spontaneous rupture of the cesophagus."

That intra-vital digestion is not the sole cause is clearly proved by the uniformly longitudinal form of the aperture and its sharply-defined edges-characters which are just the opposite of those met with in gastro-malacia. That pressure from within cannot be the sole cause is, I think, evident from the exceeding rarity of the accident despite the frequency with which the csophagus is distended by relatively enormous foreign bodies.

The conclusion to which I have arrived as the result of a careful study of existing data is, that the two main factors that are operative in causing rupture of the macroscopically normal gullet are (a) softening of the coats and $(b)$ sudden increase of pressure from within. The softening is due partly to intra-vital digestion, and partly (at least in the case which I observed) to inflammatory infiltration. The intra-vital digestion is to be accounted for by $(a)$ circulatory disturbance, which in my case took the form of venous thrombosis, and $(b)$ prolonged sojourn of peptic matters in the gullet from prolonged retching. The increased pressure from within is doubtless ascribable to the violent propulsion of the gastric contents into the lower part of the gullet whilst its upper outlet is obstructed by the contracted state of the muscle-in other words to want of coördination of the muscular action of the tube, probably due to exhaustion from prolonged over-activity. Whether a localised phlegmonous osophagitis-for that is the condition which existed in the case now recorded-is a constant factor in these cases, it is of course impossible to assert in the absence of microscopical details of the other cases. I believe I may lay claim to be the first to establish the existence of this condition as a possible cause of rupture of the apparently healthy gullet.

Dublin.

14 Loc. cit., p. 105.

Bath Mineral Water Hospital-at the meeting of the committee of this institution held last week it was decided to make alterations and improvements in the hospital at a cost of upwards of $£ 5000$. Our commissioner's strictures seem to have had a good effect.

The Professor of Physiology in Tübingen, Dr. Willy Kühne, who died last month, left directions that his body was to be cremated and that during the process the first movement of Beethoven's Ninth Symphony was to be performed; also that no memorial festival should be held.

\section{A CASE OF PERNICIOUS AN EMIA FOLLOWING ON TRAUMATIC STRICTURE OF THE SMALL INTESTINE.}

BY ARTHUR E. BARKER, F.R.C.S. ENG. \& IREL., PROFESSOR OF TRE PRINCTPLES AND PRACTICE OF SURGERY A UNIVLRSITY COLLEGE AND SURGEON TO UNIVERSITY COLLEGE

(With Pathological Report by W. Hunter, M.D.)

A CAREFul perusal of Dr. William Hunter's most suggestive essays on pernicious anæmia has convinced me that the following case ought to be put on record. I do not feel competent to pronounce on the general questions which this writer so ably raises, but the case appears to me to lend strong support to his views as far as it goes. It has also some points of intrinsic surgical interest and especially the effect of cart-wheel accidents upon the intestine short of actual rupture. The notes and observations on the blood, \&c., were accurately kept by my house surgeon, Dr. F. H. Thiele, whose abstract of them forms the basis of this record. Dr. Hunter has also kindly added a report on his study of specimens obtained at the post-mortem examination which adds great interest to the case.

A man, aged 28 years, a sawyer, was admitted into University College Hospital on Feb. 5th, 1900. He had always enjoyed good health until seven years ago when he was run over by a loaded wagon. The two near wheels, which were broad, passed over the lower part of the thorax, breaking, it is stated, five ribs and splintering another. This was followed by "pleurisy and inflammation." He was ill for 14 weeks, and after this began to have the attacks now complained of. There was no history of syphilis, rheumatic fever, or tumours, but the patient had always suffered from " heartburn," which had been worse since the accident. The patient had always been quite temperate. He had been well fed and had lived among healthy surroundings.

On admission he was noted as being very well nourished, inclining to fat, but extremely anæmic. This was most marked in the conjunctivæ, lips, and finger-nails. An examination of the abdomen revealed no abnormality of the internal organs and only a slight tenderness and increased resistance midway between the right iliac spine and the navel. Nothing unusual could be felt from or in the rectum. His reason for seeking treatment now was extreme weakness and anæmia with periodic attacks of pain and vomiting which set in soon after the accident seren years ago. These had occurred at intervals of from a week to a month and lasted from a week to a fortnight. During these attacks pain and swelling began about two inches to the right and below the umbilicus and spread from there all over the abdomen. At the same time the patient had romiting and diarrhœa. The vomit consisted of food and green fluid which tasted bitter and sour. The motions during these attacks were much lighter in colour than usual, and sometimes very pale indeed. The pain was much relieved by change of posture in any direction. The great pallor was first noticed in the summer of 1899 , and since September, 1899, the patient had suffered from shortness of breath on exertion accompanied by palpitations. During and after September, 1899, the patient was prevented from working for about 10 weeks by vomiting and diarrhoea. On admission the temperature was $99.4^{\circ} \mathrm{F}$. and the pulse was 112 . This was about the average for nearly a week, when the fever slightly increased to about $100^{\circ}$ or a little over this. He then (Feb. 17th) had the first attack of pain since admission. It began at the point described and spread all over the abdomen, lasting about one and a half hours. He vomited at this time both food and bile, and had a loose stool without any undigested food or fat and not offensive. Dr. Thiele's analysis of the blood showed red corpuscles $2,000,000$, white 54,000 , and hæmoglobin 30 per cent. The optic discs were now examined and were found to be normal. On Feb. 16th the stomach was washed out, but showed nothing abnormal. On the 17th a hæmorrhage was noticed in the left eye above and to the outer side of the optic disc. Pain and vomiting occurred on the previous night. The vomited matter was bile-stained with very little undigested food. It contained free hydrochloric acid. Reduced iron was now 
given. The diet was full and was eaten with appetite except in the morning. The patient was growing paler. On the 21st he vomited twice with but little pain. The urine had been free from albumin since admission. It was acid and of normal colour with an excess of indican. Urea 2.5 per cent. There had been no loss of flesh, but the pallor was increasing very much and severe headache had been complained of for some days. On the same day (the 21st) an examination of the blood showed red corpuscles $1,000,000$, hæmoglobin 20 per cent., and white corpuscles $1: 450$. The blood itself to the naked eye was very thin and watery; megalocytes and microcytes, but no nucleated red corpuscles, were seen. Feeling now satisfied that there was some serious lesion high up in the small bowel, probably of the nature of a stricture, I decided to explore the abdomen.

Operation was performed on Feb. 22nd. The abdomen was opened in the mid-line above the umbilicus. The first thing noticed was a coil of enormously distended and thickened small intestine of white colour, which for the moment was taken to be the stomach. It was seen, however, on nearer inspection to lie below the colon, but to overlap it above. The distension terminated to the right of the spine in a sharp kink among many old smooth adhesions,

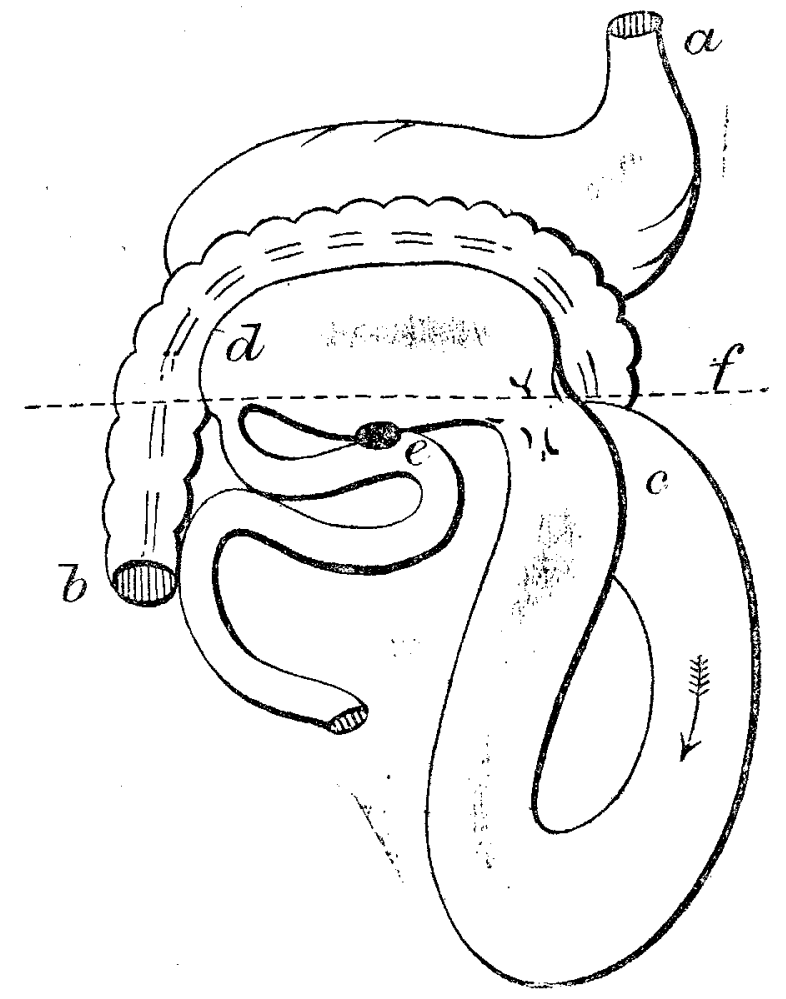

a, Stomach. $b$, Colon. $\quad c$ Dilated jejunum, coil $? \mathrm{ft}$. long. $d$, Dilated jejunum above stricture. $e$. Anastomosis between dilated and healthy jejunum. $f$, obvious course of cartwheel.

and below this the intestine was normal and empty. On pushing the finger into the distended coil so as to invaginate it a narrow stricture could be felt at the kinked spot. To the left the dilated coil was held down to the spine by adhesions which led me to the conclusion that I was dealing with the first part of the jejunum as it emerged from under the plica. These adhesions, too, were all smooth and evidently old. I now anastomosed the distended loop with the empty portion below the kink and stricture. This was done by a double row of silk sutures in the usual way. In making the openings in the contiguous loops the contrast between the thickwalled upper portion and the thin-walled normal viscus below was very striking. The abdomen was now closed in with silk sutures. The operation lasted 50 minutes and towards the end the condition of the patient was not very good. On this account a pint of normal saline solution was injected hypodermically during its concluding stages. After the operation there was a good deal of pain which was relieved by morphia, after which the patient fell asleep. The pulse was 116, the temperature was $102 \cdot 2^{\circ}$, and the respiration was 38 . The next morning he was not so well. The temperature was $102.8^{\circ}$ and the pulse was 136 . Death took place at 5.15 on the 24 th.

The condition of things at the post-mortem examination was most instructive. The anastomosis left nothing to be desired as to water-tightness. Union was sound as tested in various ways and there was no peritonitis. The point of anastomosis lay in front of the spine nearly in the middle line. It united an enormously aistended and thick-walled loop of small intestine with an empty coil lying below it. The cause of the distension was seen to be a tight stricture of the gut lying just to the right of the spinal column below the transverse colon, where the small intestine was kinked on itself as well. This kink was glued to the spinal column by many adhesions of old date. To the left of the spine the dilated coil was similarly held down by adhesions close to the termination of the duodenum. This had given the wrong impression at the operation that the distended coil was the first foot or so of the jejunum as it emerged from under the fold containing the mesenteric artery. On further examination now it was seen that the point glued by adhesions to the spine corresponded to a spot about seven feet below the commencement of the jejunum and that the whole of the left side of the abdomen was filled by a very much dilated and thick-walled coil of the latter some seven feet long. This coil was distended to about the size of an adult forearm with pale yellow fluid which was only escaping slowly through the anastomosis into the healthy bowel below (vide diagram). The crushing injury from the cart-wheel had also caused adhesions between the transverse colon and adjacent small intestine and had destroyed the upper end of the right kidney which was converted into a fibrous mass. The second part of the duodenum had also been damaged by the wheel. Its serous coat had been cracked in places, leaving the muscular coat exposed. These patches were glazed over and healed but stood out clearly against the normal bowel. The cracks reminded one of what is seen in cases of intussusception where the serous coat gives way, but I had never before had an opportunity of seeing such a crack healed. It was seen in this case that such a lesion could be repaired without the muscular coat adhering to any surrounding organ. The liver as tested by Dr. W. Hunter, who was present, contained a large excess of iron. On opening the distended bowel the stricture was found to be due to the contraction of an ulcer produced by the crushing of the mucous membrane where the cartwheel caught it against the spine. It was annular and the lumen was only about the size of a cedar pencil. Other healed ulcers were seen above it and some partially healed. The seven feet of bowel between the stricture and the duodenum were enormously dilated and fall of pale yellow fluid like thin custard. This was taken away by Dr. Hunter for analysis. On examining the mouth and nose the ethmoidal sinuses were found to be full of pus. In all these factors the conditions were present which Dr. Hunter believes to be at the root of pernicious anæmia-suppuration connected with the mouth, a stricture of the intestine retaining the contents long enough to ensure their decomposition, and the formation of a specific poison.

The cause of death was probably the escape of the poison through the anastomosis and its rapid absorption by the previously healthy and empty intestine as indicated by high temperature and rapid pulse. One can only regret that no opportunity had been given for the performance of the same operation some months earlier before the patient had become so profoundly overcome by the disease.

\section{Pathological Report.}

By Wilutam Hunter, M.D. Edin., F.R.C.P. Lond., JOINT LECTURER ON PRACTICAL MEDICLNE, CHARING CROSS HOSPITAI SENIOR ASSISTANT PHYSICIAN, LONDON FEVER HOSPITAI.

I am indebted to Mr. Barker for the opportunity of seeing the case above described, which has proved to be one of especial interest in relation to the pathology of pernicious anæmia. I only saw the patient a few hours before bis death when he was too ill to be thoroughly examined. Nevertheless, from the account of his illness, his appearance, the degree of oligocythæmia (far greater than any ever caused by ordinary malnutrition or wasting disease however profound). and the character of his gastro-intestinal symptoms, 1 regarded the case as one of pernicious anæmia. This view was fully confirmed by the result of the necropsy, and still further by the subsequent investigation, both microscopic and chemical, which, thanks to Mr. Barker's courtesy, I was enabled to make on the material obtained from the case.

Nature of examination.-I was afforded the opportunity of being present at the necropsy, and I append the notes which I then made. I have subsequently examined microscopically the following tissues and organs-viz., blood, spleen, lymph 
glands (gastric and mesenteric), liver, kidney, tongue, gums, teeth, stomach, small intestine, and colon; also chemically the liver, spleen, and kidney for iron; and, lastly, both microscopically and chemically the stomach contents. The number of sections so far microscopically examined has been close on 200.

Summary of results.-1. There were characteristic pigment changes with large excess of iron in the liver and kidney and intensely deep colour of bile denoting excessive hæmolysis. 2. The ordinary blood changes of pernicious anæmia, including the presence of nucleated red corpuscles in the blood, spleen, and glands. 3. Dental decay and necrosis with pus sacs at the roots of the teeth, collection of pus in the ethmoidal sinuses, and foul granulations around a necrotic tooth. 4. Stomach : fatty infiltration, degeneration, catarrh, and desquamation of the glandular cells; presence of cocci (oxyntic cells least affected) in the perivascular lymphatics of the submucosa at certain parts. 5. Intestine: there were no post-mortem changes. There were a number of ulcers in various stages (active, healing, and healed) above the constricted portion of the gut. At other parts there was thinning of the mucosa; the cells of the glands generally were normal; at parts there was superficial inflammatory necrosis of the mucosa due to the presence of organisms, at others replacement of glands by cicatricial tissue amidst which strepto. coccal organisms were numerous, and at others the presence of cocci in the perivascular lymphatics of the submucosa 6 . Colon: there were no post-mortem changes. The lymphoid elements of the mucosa were well preserved and staining was normal. (a) There was intense degeneration and necrosis of the glandular cells, hardly a normal cell remaining. The cells represented by granular detritus were crowded with organisms, most of them cocci, only a few bacilli ; $(b)$ cocci, both single and in chains, were very abundant in the deeper parts of the mucosa around the base of the glands (they were absent from the superficial mucosa) and at parts they were very numerous in the lymphatics of the submucosa. Their streptococcal nature in parts was very obvious. 7. Pus of ethmoidal sinus: "Staphylococcus pyogenes aureus and bacillus coli communis, the latter being probably a post-mortem contamination" (Dr. Eyre, Bacteriologist, Charing-cross Hospital). 8. Stomach contents : chemically there was neither free hydrochloric acid nor butyric acid. Lactic acid was present. Micro sopically there were numerous organisms, including mouth bacilli. All of them were decolourised by Gram's method with the exception of a streptococcus form (streptococcus longus). The contents were deeply bile-stained, resembling closely in appearance and character the contents of the jejanum. No caltures were obtainable owing to excess of formalin. 9. The percentage of iron in the liver was 0360 ; in the spleen, 0.069; and in the kidney, 0.330 . To show the notable increase of iron in the liver and kidney $I$ append for purposes of comparison the results of a similar analysis recently made in a case of gastric cancer - a case which resembled pernicious anæmia in the high degree of lemon colour and in the absence of any notable emaciation. Percentage of iron in the liver, spleen, and kideny in the gastric cancer : liver, 0.022 ; spleen, 0.013 ; and kidney 0.003 .

Necropsy. -The necropsy was performed 12 or 15 hours after death. The weather was cold. There were no postmortem changes. The body was fairly nourished. The blood was watery. The liver weighed $4 \mathrm{lb} .10 \mathrm{oz}$. and was fatty; the centre of the lobules was pale and the periphery was rust-coloured. A piece of liver placed in sulphide of ammonium gave marked iron reaction (blackening). The gall-bladder was filled with extremely deep golden-yellowcoloured bile. The mucosa was normal. As to the kidney, the right weighed four and $a$ half ounces and showed a cicatrix at the lower end, the result of an old crush. The left weighed seven ounces. It was comparatively enlarged. The spleen weighed five ounces; it was red and firm, not soft. The stomach contained 120 cubic centimetres of bile-stained contents with food. There was no cadaveric softening. The mucosa showed punctiform hæmorrhages ; there was considerable increase of mucus. The duodenum and intestine contents were fluid and very deeply bile-stained. The jejunum was much dilated and the walls were considerably hypertrophied above the point of narrowing (from six to seven feet below the stomach). The mucosa above the stricture showed a number of irregular ulcers, some of them cicatricial, others partially healed, and others still showing hyperæmic edges. Elsewhere the mucosa of the intestine, colon, and rectum showed nothing obviously abnormal. In the gastric and mesenteric glands there was no trace of hæmorrbages. Microscopically there was no pigment. The heart muscle was red and byaline; there was no tabby. cat striation. The musculi papillares of the left ventricle were hypertrcphied. There were a few punctiform hæmorrhages under the epicardium. The tongue was very soft on the sides; there were no ulcers. There were compound papillæ on the back part of the dorsum in front of the epiglottis slightly red and prominent. The tonsils were red. The cesophagus was normal in appearance. With regard to the teeth the incisors and canines were small, regular, and pearly white, looking quite normal. The bicuspids and molars were very bad, represented for the most part by necrotic atrophied-looking stumps, the gums around which presented a peculiar whitish sodden appearance. In the right upper jaw the first bicuspid was represented by a black stump. very small and atrophied (10 millimetres long by five millimetres wide), with a small abscess sac of about the size of a pea at its apex. The fang at the apex was dead and necrosed. The second bicuspid and first molar were represented by black fangs, the second molar had a black carious cavity in the crown, and the third molar a dark carious cavity on the outer side of the crown. In the jaw beneath these teeth was a large abscess sac 13 millimetres in diameter communicating by a fistulous sinus with the root of the second bicuspid or first molar above; bare bone was felt at the upper end of the sinus. In the left upper jaw there was a similar white sodden appearance of gums immediately around decayed roots. The wisdom tooth alone remained; the gum around it was swollen and at the back part was detached from the tooth. It was red, granulating, and inflamed; the fang of the tooth beneath was exposed and carious. On opening the left orbital cavity a large quantity of pus welled up, appearing at first as if coming from the orbital cavity; afterwards it was found to come from the ethmoidal sinuses. There were no subdural bæmorrhages in the brain. With regard to the lungs there were subpleural, punctiform hæmorrhages near the base. In the marrow of the long bones there was transformation of yellow into red marrow.

Remarks. - The case as a whole appears to me to support in a striking manner the conclasions which I pat forward in the recent studies to which Mr. Barker refers. These observations denoted, I concluded, the infective nature of the condition termed pernicious anæmia, "the infection being confined to the alimentary tract, chiefly the stomach, no part of that tract from mouth to anus being safe from it." The source of infection I traced to the mouth, arising either within the mouth itself "in connexion with long-continued and neglected cario-necrotic conditions of teeth, sometimes possibly from stomatitis arising from other causes-e.g., drain poisons." The infection was "chiefly streptococcal, probably deriving its special (i.e. hæmolytic) characters from being of a 'mixed' character, the infection the more readily occurring if the stomach or intestine were already from any cause the seat of disease."

The anæmia was not due to any mere disturbances of nutrition arising from the stomatitis, glossitis, or any conditions of gastritis or enteritis which might be, and often were, found, but to the destruction of blood occasioned by the special infection. The whole group of conditions in the alimentary tract "were the local lesions of an infection, chiefly cæcal, the anæmia being the result of the destructive action of the poisons absorbed into the blood." Mr. Barker's case appears to me to present points of special interest in relation to the foregoing conclusions.

1. Nature of the ancmia. - That the case was one of pernicious anæmia is, I consider, conclusively established by the results of chemical analysis, showing a characteristic increase in the percentage of iron in the liver (also in the kidney). Microscopically the pigment was found within the liver cells in the outer zone of the hepatic lobule, with characteristic fatty changes in the centre of the lobule. The anæmia was thus hæmolytic in its nature.

2. Mode of deve'opment.-The patient suffered from more or less abdominal discomfort from the time of his accident seven years before without the development of any special degree of anæmia till the previous summer-i.e., seven months-before his death. His great pallor then became noticeable and he soon after began to suffer from shortness of breath and palpitation-i.e., five months before death. The conclusion which I form, then, is that at the time of his death be was in his first year of illness from pernicious anæmia. In his case the unhealtby conditions 
of some part or other of the alimentary canal which according to my studies always precede and are necessary to successful infection, were created in the intestine above the point of stricture. As shown by the character and severity of his gastro-intestinal symptoms (pain and vomiting) these unhealthy conditions had existed from the time of his accident seven years before and it is, I consider, exceedingly probable that some of the healed ulcers found post-mortem above the seat of stricture were remains of lesions resulting therefrom. With comparative suddenness there was superadded to his general abdominal discomfort the feature of intense pallor with all the symptoms-e.g., palpitation, breathlessness, diarrhoea, and vomiting, varying febrile attacks (see Mr. Barker's account of the illness in September, 1899) which are so characteristic of pernicious anæmia, and from that time forward what troubled him most-what he sought admission into hospital for-was his extreme weakness and anæmia complicated by periodical attacks of pain and vomiting connected with his intestinal condition. This relation of events-a history of antecedent gastric or intestinal trouble extending usually over many years, more or less suddenly followed by a rapidly developing anæmia out of all proportion to the actual extent or severitg of lesion existing in the stomach or intestine-I find in $\mathrm{my}$ experience of the disease to be the typical mode of development of pernicious anæmia. And this more or less suddenness of development, with the extraordinarily high degree of anæmia (exceeding anything ever met with even in the severest forms of wasting anæmia) are the clinical features which I have come to regard as denoting the supervention of a new factor-viz., successful infection of some part or other of the alimentary canal.

3. Evidtnces of infection. - In the present case the evidences of infection of the mucosa, to a slight extent of the stomach and to a still greater extent of the intestine and colon were undoubted - notably (1) the small areas of the superficial ulceration and necrosis with inflammatory changes in certain parts of the mucosa of the small intestine, with presence of organisms confined to these areas and to the lymphatics of the submucosa; and (2) the very striking degeneration and necrosis of the cells of the tubules in the colon associated with presence of organisms also confined to the tubules and to the subjacent lymphatics of the mucosa and submucosa.

That the invasion of the mucosa was no mere post-mortem phenomenon is, I consider, clear from the following: $(a)$ In the case of the stomach only in one part microscoped was there slight superficial post-mortem change in the mucosa, and at this point no organisms at all were found. On the other hand, the organisms were found in the lymphatics of the mucosa at prolated parts where no postmortem changes were shown. (b) In the case of the small intestine the cells of the tubules generally showed no change and no organisms were present in them. On the other hand, where the organisms were present they were surrounded by evidences of inflammatory reaction- $-\nabla i z .$, nuclear fragmentation and necrosis. (c) In the case of the colon the organisms were confin:d to the degenerated and necrosed cells of the glands and to the lymphatics underlying them. They were not present amidst the lymphoid tissue of the general mucosa.

4. Nature of infection.-As regards the nature of the organisms present and their relative importance any decision from their microscopical characters alone is naturally impossible. The contents of stomach and intestine were much alike in character and both were bile-stained, so that it is certain that the ordinary intestinal organisms (bacillus coli) were present in the stomach no less than in the intestine. In the mucosa, and especially within the lymphatics, however, the organisms present were not bacilli but cocci, and especially streptococci (Zeiss, $\frac{1}{1}$ oil immersion), and a streptococcus was also present in the stomach contents. As this organism is undoubtedly pathogenic I am disposed to attach to it the chief importance. The infection of the mucosa was chiefly coccal and streptococcal.

5. Source of infection. - On this point- the one to which my recent observations more especially referred-no information was forthcoming from the history of the patient. He was too ill to be questioned. He had been well fed and had lived among healthy surroundings. With regard to any dental or oral trouble his wife informed me in reply to inquiry that he had not suffered in that respect. The examination, cursory in character, which I made at the time I saw him a few hours before his death, when he was already sinking, seemed to bear out this statement, for the front teeth which he showed me on opening his mouti seemed exseptionally good and healthy, so much so that I mentally registered the case as one affording no support to the recent conclusions regarding the prevalence of decayed teeth and their importance as a possible source of pyogenic infection in pernicious anæmia.

As it turns out, I cannot but regard the case as a most remarkable one in this relation, for $I$ found at the necropsy that the front teeth were the only good ones. The remainder were for the most part represented by black roots lying in sodden white gums. At the roots of these, in one side of the jaw alone, were two abscess sacs, the larger being of the size of a small hazel nut. Moreover, on opening the left orbital cavity pus welled out in quantity from the ethmoidal sinuses. Of this condition of mouth or nose there was not, be it noted, the slightest suspicion during life and not the slightest symptom. This was one of the points to which I drew special attention in the observations recently recorded. I considered it "all-important in all cases of commencing anæmia that special attention should be directed to the condition of the teeth ..... by removal not only of old stumps, but also of all black teeth, and of teeth showing commencing cario-necrosis ...... these precautionary measures being necessary, irrespective of anj statements made by the patient as to the degree of discomfort his teeth are causing. For in no single case observed, however bad I found the teeth to be, was my attention drawn to the teeth by the patient or any complaint made of them by him. There is a stage in pyogenic conditions as in other forms of infection when local reaction-e.g., pain or inflammation-is absent or insignificant at the very time when the general septic effects are most marked."

The case just recorded bears out-if possible even more fully than I had anticipated-the correctness of these statements. Without occasioning the slightest local discomfort there existed a profoundly septic condition both of jaw and ethmoidal sinuses. How long these decayed teeth had existed I have no means of knowing. But I note with interest the statement in his history that "he had always suffered from 'heartburn' worse since the accident," a symptom denoting existence of chronic gastric catarrh. The close relationship between dental cario-necrosis and gastric catarrh is the point which I have recently had occasion to elucidate. The two conditions are precisely those most favourable to infection of the mucosa of the stomach, and ultimately, if the conditions be favourable, as in the present case, to infection of the intestine lower down. For on the one band there is diminished resistance on the part of the stomach from the diminished acidity of gastric secretion consequent on the catarrh; while on the other hand there is increase of dose from continuous swallowing of pus organisms from the necrotic teeth. In the present case both these conditions were met. The patient bad infection of the mouth, and the gastric contents contained no free hydrochloric acid.

\section{SUMMARY.}

The relations of events in the case I would then summarise as follows:-

1. A man, temperate, well fed, and living in healthy surroundings.

2. Bad teeth causing alternately alveolar and ethmoidal suppuration without at any time occasioning local discomfort.

3. Always suffered from "heartburn" (denoting chronic gastric catarrh with diminished acidity of gastric juice).

4. Accident causing stricture of jejunum.

5. More or less severe abdominal and gastric symptoms lasting six years.

6. More or less rapid supervention of the features of pernicious anæmia nine months before death.

7. Post mortem (1) dental decay with local complications-e.g., alveolar and ethmoidal suppuration; and (2) definite infection (coccal and streptococcal) of the mucosa of the intestine and colon, with definite catarrhal, inflammatory, and necrotic changes-to a less extent of the stomach.

The late Mr. J. Flint South, F.R.C.S.-Mrs. C. Stuart Andreae and Miss Mary F. South have forwarded to the treasurer of St. Thomas's Hospital a donation of $£ 1000$ to endow, in perpetuity, the "South Bed, as a memorial of the late Mr. J. F. South, who was for some years surgeon to that institution." 


\section{A CASE OF ULCERATIVE ENDOCARDITIS, WITH RECOVERY UNDER THE USE} OF ANTI-STREPTOCOCCIC SERUM.

By J. MICHELL CLARKE, M.A., M.D. CANTAB., F.R.C.P. LOND.,

PROFESSOR OF PATHOLOGY, UNIVERSITY COLLEGE, BRISTOL; PHYSICIAN TO THE RISTOL GENERAL HOSPITAL.

As the employment of anti-streptococcic serum in ulcerative endocarditis is still on its trial $I$ bave thought it worth while to report the following case in which it was successfully used. The patient was a single woman, 22 years of age. She had enjoyed good health until the age of 18 years, anæmic. The temperature was normal and the pulse was 110 and weak. The lower part of the left side of the chest was slightly contracted as a result of the attack of pleurisy. The heart's apex gave a forcible impulse in the nipple line in the left fifth space; dulness extended transversely from the nipple line to the right border of the sternum and upwards into the second left intercostal space; and a loud systolic murmur was present at the apex and right base and was audible at the angle of the left scapula. The liver was slightly enlarged. The urine contained no albumin.

The patient was kept in bed; the temperature rose two or three times in the evening to $100^{\circ}$ or $101^{\circ} \mathrm{F}$., and she appeared to be doing well, when on Dec. 6th she had a rigor and the temperature rose to $103^{\circ}$. On the 7 th a small patch of broncho-pneumonia developed just below the angle of the right scapula and she expectorated a little blood-stained sputum. In the light of the subsequent progress of the illness this attack was probably due to an infarct into the

FIG. 1.

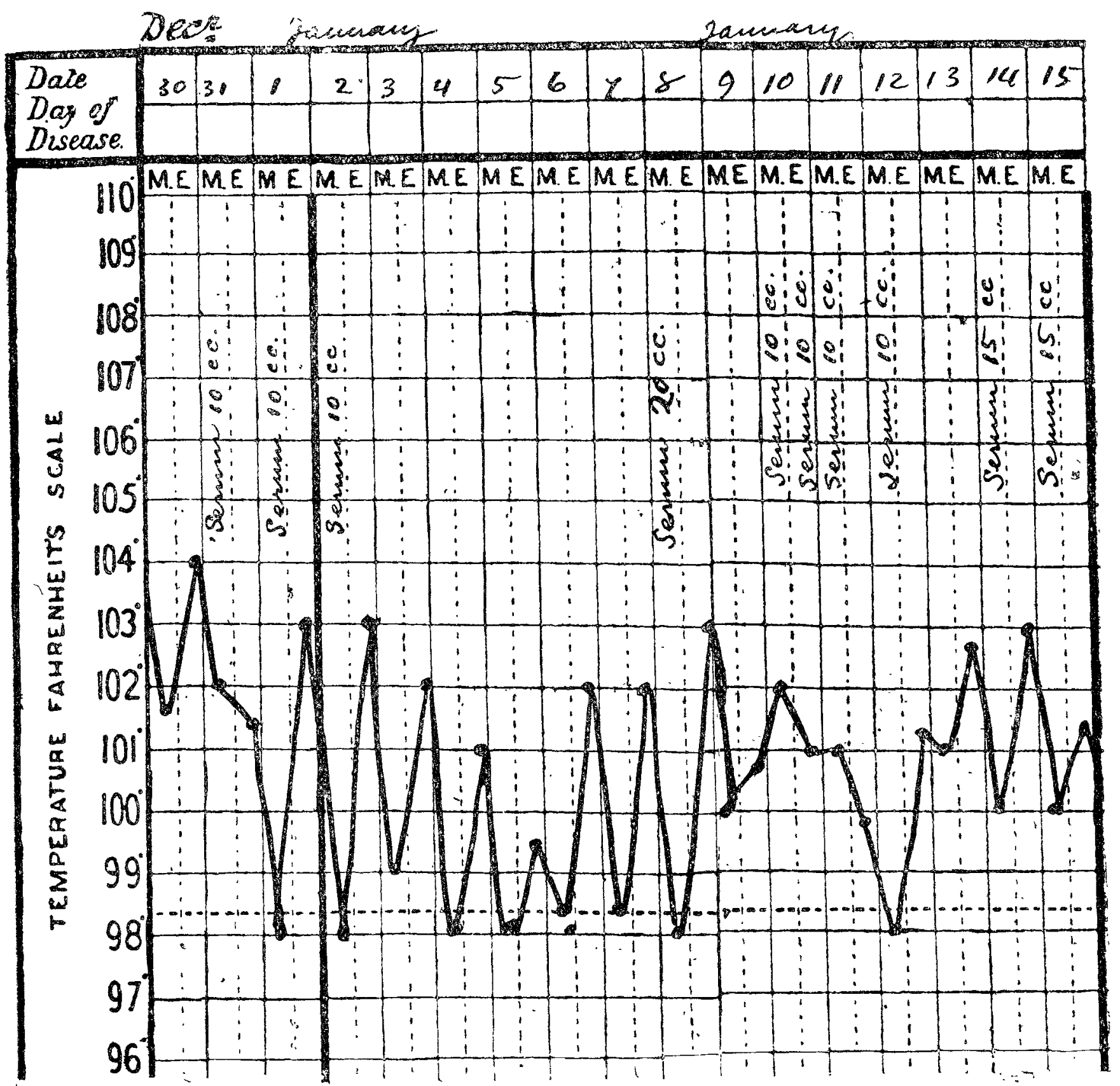

when she had what was called an attack of muscular rheumatism which laid her up in bed for six weeks. She then improved and was able to get about for two weeks, but developed pleurisy with effusion on the left side. She recovered from this and subsequently remained fairly well, but was delicate and liable to suffer from cough and from shortness of breath on exertion. She came to me on Nov. 14th, 1899, complaining of weakness, shortness of breath, pain in the præcordial region, and slight swelling of the ankles. She also said that during the previous fortnight she had felt hot in bed at night and had had two attacks of slight shivering accompanied by blueness of the lips and pallor of the face. She was tall, thin, and lung. The temperature remained at from $102^{\circ}$ to $103^{\circ}$ for three or four days and then fell to normal and remained so for about a week when it began to rise again in an irregular fashion. The subsequent course of the temperature was as follows from the 19th to the $28 \mathrm{th}, 1899$, inclusive :-

Date. Morning. Evening. Date. Morning. Evening. Dec. 19th ... $\quad-\quad \ldots 102.0^{\circ} \mathrm{F}$. Dec. 24 th ... $97.0^{\circ} \mathrm{F}$. ... 104.0 F。

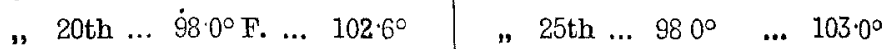

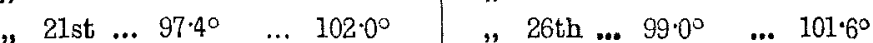
$\begin{array}{lllllllllll}" & 22 \mathrm{nd} \ldots & 968^{\circ} & \ldots & 1030^{\circ} & \# & 27 \mathrm{th} & \ldots & 97.0^{\circ} & \ldots & 101 \cdot 4^{\circ}\end{array}$

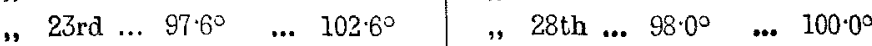

